\title{
COOPERATIVISMO E PROFISSIONALIZAÇÃO DA GESTÃO EM UMA COOPERATIVA AGROPECUÁRIA
}

\author{
Aline Barasuol $^{1}$ \\ Amábile Tolio Boessio ${ }^{2}$ \\ Gilmar Jorge Wakulicz ${ }^{3}$ \\ Viviane Flaviano ${ }^{4}$
}

\section{Resumo}

Este artigo tem por objetivo analisar se o gestor contratado da Cooperativa Agropecuária Júlio de Castilhos, COTRIJUC, ao assumir - cargo, compreende as especificidades de uma organização cooperativa e se isto auxilia no processo de profissionalização da gestão. A Cooperativa localiza-se na região central do estado do Rio Grande do Sul/Brasil e possui um quadro social com 2.941 cooperados. O estudo apresenta abordagem quanti-qualitativa, utilizando-se ainda de um estudo de caso. A partir da análise dos resultados, foi constatado que $85,71 \%$ dos gestores entrevistados foram selecionados através de recrutamento interno para os cargos de gestão e esses estão atuando na mesma, em média 12,3 anos. Os gestores entrevistados conhecem e entendem o seu importante papel na organização, pois são eles que dão o suporte necessário para que a cooperativa continue ativa no mercado. Dessa forma, embora não tenha um programa de educação cooperativa, a Cooperativa vem proporcionando ações informais de educação/ capacitação cooperativa para seus colaboradores, por meio dos conhecimentos transmitidos dos colaboradores mais antigos aos novos colaboradores.

Palavras-chave: Cooperativas. Gestores contratados. Recrutamento e treinamento.

\footnotetext{
1 Graduada em Tecnologia em Gestão de Cooperativas (UFSM). Mestranda em Extensão Rural (UFV). E-mail: abarasuol@hotmail.com

2 Graduada em Tecnologia em Gestão de Cooperativas (UFSM). Mestranda em Extensão Rural (UFV). E-mail: amabiletolio@hotmail.com

${ }^{3}$ Graduado em Ciências Econômicas (UFSM). Mestrado em Engenharia de Produção (UFSM). Doutorado em Engenharia de Produção (UFSM). Prof. Assistente da Universidade Federal de Santa Maria (UFSM). E-mail: gilmarwakulicz@politecnico.ufsm.br

${ }^{4}$ Graduada em Gestão de Cooperativas (UFV). Mestrado em Administração (UFSM). Email: vivianeflaviano@gmail.com
} 


\title{
COOPERATIVISM AND PROFESSIONALIZATION OF MANAGEMENT IN AN AGRICULTURE COOPERATIVE
}

\begin{abstract}
The main goal of this study is to analyze the manager of the Cooperativa Agropecuária Júlio de Castilhos - COTRIJUC. We will analyze if the managers understand the specifics of a co-operative and if these specifics help in the professionalization process. The COTRIJUC is located in the middle of the state Rio Grande do Sul/Brazil and it has 2,941 people associated. The study encompasses an approach qualitative and quantitative and a case study. Analyzing the results, we realized that $85.71 \%$ of the managers interviewed were selected by internal recruitment. Also, these managers are working for about 12.3 years. It was possible to see that the managers have knowledge about their function inside the organization because they are responsible for the activities, profits, and help to the associated of the organization. Even though COTRIJUC does not have a co-operative education program, it has been giving informal educations actions/co-operative training to the managers through the exchange of knowledge between old managers and the new ones.
\end{abstract}

Key words: Cooperatives. Hired Managers. Recruitment and training.

\section{INTRODUÇÃO}

O processo de globalização ao qual se está vivendo e o presente cenário econômico mundial vem impondo às organizações a sobrevivência em um ambiente externo cada vez mais competitivo. A luta pela permanência no mercado exige das organizações o desafio de rápida e eficiente adaptação ao cenário, cada vez mais incerto e em constante mudança. "Concorrência acirrada, pressão constante, necessidade de acompanhar as inovações, conflitos, essa é a realidade vivida por milhares de organizações e seus respectivos colaboradores, tendo em vista o dinamismo do mundo e das empresas" (ROMÃO; CONFORTI; LIMA, 2012, p. 4).

Neste cenário, é imprescindível que as cooperativas se adaptem a essas transformações. Entretanto torna-se evidente uma complexa realidade que envolve essas organizações, pois são 
organizações diferenciadas, alicerçadas em princípios doutrinários. A identidade desse de empreendimento é formada através de um aspecto principal, o equilíbrio entre três dimensões - social econômica e ambiental -, e essa característica principal exige uma gestão diferenciada da cooperativa, para que haja um real equilíbrio entre suas dimensões e a efetiva permanência no mercado globalizado.

Em decorrência disso, o setor cooperativista vem enfrentando dificuldades de adaptação ao novo contexto e colocando em risco a sua sobrevivência no mercado competitivo e de grande complexidade. Este fato vem exigindo mudanças no ambiente interno das cooperativas para que se tornem organizações mais competitivas, e isto implica na profissionalização da gestão. Neste sentido, as cooperativas têm um grande desafio já que sua gestão está fundamentada em seus princípios doutrinários, dessa forma, a estrutura organizacional está desenhada de acordo com seus objetivos constitucionais, ou seja, quem está na gestão da organização e tem o maior poder de decisão são os seus cooperados, que assumem um duplo papel, dono e usuário.

O processo decisório das cooperativas remete a elas um desafio para se manter no meio hipercompetitivo que estão inseridas, pois se trata de uma estrutura que apresenta um processo mais lento do que as demais organizações, o que exige das cooperativas maior rapidez no processo de gestão e nas tomadas de decisão. 0 processo decisório tem sido discutido por alguns autores, pois tal trata-se de um princípio doutrinário - Gestão democrática pelos membros. Antonialli (2000) traz as críticas de Zylbersztajn, Bernardo e Jank que exigem desse princípio uma reformulação "na tentativa de imprimir a racionalidade econômica e administrativa nas cooperativas, buscando eficácia interna e externa para alcançarem maior competitividade em relação às empresas não-cooperativas" (ZYLBERSZTAJN (1994), BERNARDO (1996) e JANK (1997) apud ANTONIALLI, 2000, p. 138 ).

Já o Serviço Nacional de Aprendizagem do Cooperativismo - SESCOOP (2008) apresenta um problema citado por Jank (S/D). Esse está relacionado com a necessidade da profissionalização da gestão, porque ainda existe uma incerteza por parte das cooperativas em diferenciar propriedade de controle. De fato a propriedade é dos associados, porém o controle precisa ser exercido por equipes competentes capazes de tomar decisões no longo prazo baseadas no comportamento do mercado. Através do exposto, ficam visíveis deficiências e dificuldades na adaptação das cooperativas no cenário econômico, já que as mesmas estão alicerçadas em 
princípios doutrinários. Os mercados desse cenário econômico estão cada vez mais rigorosos e agressivos, exigindo das cooperativas, uma maior agilidade e profissionalização na gestão.

Quando está em discussão a profissionalização das cooperativas é importante ressaltar dois aspectos fundamentais: o primeiro está relacionado à profissionalização da direção eleita da cooperativa e 0 segundo a contratação de profissionais especializados para dar suporte decisório aos dirigentes. Para que a gestão interna da cooperativa esteja de acordo com as necessidades complexas exigidas pelo mercado competitivo, não se pode dar espaço na organização para o amadorismo.

De acordo com Rodrigues (2008, p. 333) "[...] os líderes eleitos definem 0 rumo, mas os profissionais pavimentam 0 caminho". Essa afirmação traz à tona uma preocupação pertinente das cooperativas, encontrar no mercado capitalista, profissionais capacitados, que além de dar suporte necessário nos negócios e às lideranças eleitas, estejam também em conformidade com o objetivo singular da cooperativa. Para isso, é importante investir na formação de recursos humanos, principalmente dos gestores contratados, pois estes precisam conhecer e entender a organização da qual fazem parte, ainda mais se os profissionais contratados não trazem consigo uma cultura de cooperação, o que pode colocar em risco a sobrevivência da organização cooperativa no cenário econômico.

A relevância desse assunto é apresentada por Haas e Reisdorfer (2012). Os autores fizeram uma análise em sete cooperativas da região de Cerro Largo no Rio Grande do Sul, onde questionaram o nível de conhecimento dos dirigentes sobre cooperativismo, mostrando que apenas $14 \%$ consideram ter um conhecimento bom sobre o assunto. É mostrado também pelos autores, que os próprios dirigentes reconhecem na entrevista a deficiência sobre o conhecimento de cooperativismo e que precisam aprimorá-lo. Devido à importância deste tema, busca-se entender: de que forma a compreensão dos gestores contratados de uma cooperativa, relacionada ao cooperativismo e à gestão diferenciada de cooperativas, auxilia na eficácia da profissionalização da gestão.

É importante salientar que o setor cooperativista agropecuário tem significativa importância na economia brasileira, pois, ao mesmo tempo em que abastece o mercado interno tem relativa participação nas exportações do país. Em detrimento disso, as cooperativas agropecuárias assumem a primeira posição, como segmento economicamente mais forte do cooperativismo brasileiro (OCB, 2012). Diante da grande expressão e relevância das cooperativas agropecuárias, tanto para a economia brasileira quanto 
para os produtores rurais, o presente artigo tem como organizaçãoalvo uma cooperativa agropecuária, a Cooperativa Agropecuária Júlio de Castilhos - COTRIJUC - localizada na cidade de Júlio de Castilhos, na região central do estado do Rio Grande do Sul/Brasil, que traz por visão, "ser a melhor opção de negócio ao cooperado na proporção da sua participação e servir como referencial competitivo" (COTRIJUC, 2012, s.p.).

A partir do exposto, o estudo tem por objetivo analisar se o gestor contratado da COTRIJUC, ao assumir o cargo, compreende as especificidades de uma organização cooperativa e se isto auxilia no processo de profissionalização da gestão. Neste sentido torna-se relevante discorrer sobre a compreensão dos gestores sobre as especificidades do cooperativismo, já que estes são os responsáveis pelo sucesso ou insucesso da cooperativa. Para Rodrigues (2008, p. 309), "não há outra saída. É preciso ser eficiente". Somente uma equipe administrativa competente e consciente da singularidade da organização em que trabalha pode gerar eficiência e competitividade para a organização como um todo no mercado.

\section{REVISÃO DE LITERATURA}

\subsection{Análise do cenário econômico mundial e a relação com as Cooperativas}

O cenário econômico mundial está em constante mudança e transformação exigindo das organizações o desafio de adaptação a ambientes cada vez mais incertos e mutáveis. Em consequência disso, os mercados estão cada vez mais competitivos e rigorosos forçando as organizações a se adequarem a esses novos fatos com muita rapidez e eficiência.

Rodrigues (2008, p. 279) afirma que está em andamento a "Terceira Guerra Mundial":

[...] a guerra por mercados, por lucros, na qual todos os países estão envolvidos, queiram ou não. $\mathrm{Na}$ qual todos os setores econômico-sociais estão lutando, sem direito à opção pela paz. Uma guerra cujas armas não são as nucleares. São as que compõem a moeda da competitividade: custo baixo, eficiência, qualidade, produtividade, preço bom. Uma guerra cujo senhor é o consumidor final, e na qual haverá vencedores e derrotados. 
E para estar nessa guerra por mercados, é exigido das organizações um diferencial, o de descobrir oportunidades no meio ao qual estão inseridas e aproveitá-las com eficiência, pois só permanecerão no mercado aqueles que souberem administrar a rapidez das constantes inovações. Com esse cenário, as cooperativas também precisam se submeter ao processo de globalização, tornando-se competitivas e eficientes para vencer a guerra por mercados. É imprescindível que elas estejam adaptadas a essas transformações para sobreviver no mercado e com isso não deixar de cumprir seus objetivos com os seus associados, não desamparar os que dependem de seus empregos e ainda não deixar de se preocupar com a comunidade.

Os autores Jerônimo, Maraschin e Silva (2006) apresentam a ideia de Cook (1995) sobre a competitividade, para este último, independente de ser uma cooperativa ou não, todas as organizações necessitam buscar maior competitividade, ou seja, se preparar e se adaptar as frequentes mudanças que ocorrem no ambiente competitivo e volátil, para isso é imprescindível que se reformulem as estratégias corporativas, pois isso possibilitará o enfrentamento das falhas do mercado. De acordo com Machado Filho et al. (2004) o ambiente competitivo tem a tendência de pressionar as organizações cooperativas a se adequar, pois, caso não se adequem às mudanças estratégicas e mercadológicas perderão espaço para os concorrentes mais adaptáveis. "Nesse contexto, a busca por minimização de custos, profissionalização, qualidade, tecnologia, produtividade, entre outros, é imperativa para o sucesso competitivo" (JERÔNIMO; MARASCHIN; SILVA, 2006, p. 79). Nesta dinâmica, como afirma Valadares (2002), é essencial para que estes empreendimentos se mantenham ativos, cooperar internamente e serem competitivos externamente (competitivo perante os mercados).

"Uma sociedade cooperativa é uma empresa constituída e dirigida por uma associação de usuários de forma democrática, objetivando a prestação de serviços tanto para seus sócios quanto para o conjunto da comunidade" (ROMÃO; CONFORTI; LIMA, 2012, s.p.). A existência da identidade cooperativa se dá por suas características singulares, que exige o equilíbrio entre as dimensões, econômica, social e ambiental. Esses aspectos não podem ser ignorados, pois só haverá uma identidade cooperativa se essas três dimensões forem respeitadas. Já, Schulze (1987, apud ANTONIALLI; SOUKI, 2005, p. 03) "[...] afirma que as cooperativas assumem essencialmente, devido aos seus princípios doutrinários, a dupla função de associação (enquanto reunião de pessoas) e de empresa 
(enquanto reunião de capital). Por outro lado, os cooperados também assumem o duplo papel de proprietário e usuário do empreendimento".

Tratando-se de uma organização diferenciada, as cooperativas vêm mostrando fragilidades e deficiências no seu modelo de gestão, comprometendo sua competitividade no mercado. Com isso, Haas e Reisdorfer (2012) concluem que uma das maiores ameaças está na adaptação do modelo de gestão cooperativista frente ao regime capitalista, a dupla dimensão - econômica e social -, e os princípios doutrinários que regem as cooperativas as colocam em uma posição diferenciada quando comparadas as empresas capitalistas. Os mesmos autores ainda argumentam que por se tratar de uma organização onde os associados são donos e usuários ao mesmo tempo, as decisões tomadas pelo conjunto de associados dificulta 0 processo decisório tornando-o lento e burocrático, totalmente ao contrário do que o atual ambiente competitivo exige das organizações.

A identidade da cooperativa se dá justamente por suas características singulares que exige uma gestão diferenciada, pois é preciso respeitar seus aspectos. Apesar do conflito existente na prática entre econômico e social, esses aspectos não podem ser ignorados, pois só existirá uma identidade cooperativa se houver um equilíbrio entre eles. Para Davis e Bialoskorski Neto (2010, p. 22) a cooperativa precisa "[...] de uma governança, cultura, e processo bastante sólidos para manter a identidade cooperativa, suficientemente flexível para adaptar-se e/ ou resistir ao mercado competitivo".

A necessidade do equilíbrio entre as duas dimensões requer das cooperativas um cuidado maior no seu gerenciamento, porque queira ou não, acabam criando-se contradições a respeito da verdadeira identidade da organização. A ineficácia administrativa em função do seu modelo de gestão vem colocando em risco a sua sobrevivência no mercado.

\subsection{Profissionalização da Gestão das Cooperativas}

Atualmente, o cenário de constantes guerras por mercados exige das organizações cooperativas comportamento competitivo, bem como muita eficiência nos processos de gestão. Diante desse contexto, não há como permanecer nessa luta sem o aporte de profissionais capacitados para participarem dos processos decisórios da organização, de acordo com suas peculiaridades, o que leva à necessidade de profissionalizar a gestão. 
O SESCOOP (2008) apresenta a ideia de Jank (S/D), de que as cooperativas necessitam profissionalizar a gestão, mas ainda existe uma incerteza por parte das cooperativas em diferenciar propriedade e controle. A propriedade de fato é dos associados, porém o controle precisa ser exercido por equipes competentes capazes de tomar decisões no longo prazo baseadas no comportamento do mercado.

Esse problema, diferenciação entre propriedade e controle, vem sendo discutido ainda por outros autores, pois se trata de um assunto polêmico, o problema está relacionado a um dos princípios cooperativistas que é a Gestão Democrática pelos Membros. Zylbersztajn (2002) argumenta que o duplo papel do cooperado, sendo este dono e usuário, é o maior problema de gestão encontrado nas cooperativas, pois não existe uma clara separação entre propriedade e controle, o que acarreta perda de eficiência gerencial na cooperativa, isso acontece ainda mais com as organizações que tem um elevado grau de complexidade, ou seja, com organizações maiores onde existe um alto número de associados e também onde aumentam os interesses e o oportunismo na relação cooperado e cooperativa.

Zylbersztajn (1994), Bernardo (1996) e Jank (1997) citados por Antonialli (2000, p. 138) criticam esse princípio e exigem uma reformulação desse, "[...] na tentativa de imprimir a racionalidade econômica e administrativa nas cooperativas, buscando eficácia interna e externa para alcançarem maior competitividade em relação às empresas não-cooperativas"(). De acordo com o exposto, apesar das cooperativas serem organizações diferenciadas das empresas de capital, elas devem implementar estratégias individuais para atuarem com sucesso no mercado competitivo, todavia, devem sempre preservar suas particularidades.

Mas como profissionalizar a gestão da organização cooperativa sem perder sua identidade em um cenário instável e complexo? Como sobreviver no mercado competitivo com eficiência? Quais os mecanismos para inserção na economia globalizada? Essas são questões discutidas pelas cooperativas do mundo todo, são problemas que precisam ser solucionados para que as cooperativas continuem competindo com eficiência na guerra por mercados.

Rodrigues (2008) afirma que não se pode profissionalizar a gestão de uma cooperativa como outra empresa qualquer, pois ela não é. O autor ainda insiste que,

o cooperativismo é uma doutrina que tem princípios dogmáticos universais, como 
controle democrático, retorno das sobras, remuneração limitada do capital. $\mathrm{Na}$ realidade, são princípios que orientam a ação das cooperativas e que Ihes dão um perfil diferenciado de qualquer outro tipo de empresa. Trata-se de uma questão conceitual que implica um conjunto de contradições em que, se não for claramente assimilado pelos cooperativistas de uma maneira geral, se corre o risco de perder a identidade (RODRIGUES, 2008, p. 245).

Quando está em questão a profissionalização da gestão nas cooperativas, existem dois aspectos importantes, um está relacionado à profissionalização da direção da cooperativa e outro está ligado à contratação de profissionais especializados para auxiliarem no processo decisório dos dirigentes. A necessidade de profissionalização dos dirigentes das cooperativas é uma questão de sobrevivência para o futuro. As cooperativas não podem mais ser administradas por amadores, curiosos ou aprendizes em um mundo onde os negócios estão extremamente complexos (HAAS; REISDORFER, 2012). Para se ter segurança na tomada de decisões os dirigentes precisam estar em constante busca pelo conhecimento e aprimoramento, pois existem aspectos históricos, culturais, políticos, organizacionais, econômicos, legais, tributários e financeiros que precisam ser levados em consideração no processo decisório da direção, para a organização se manter competitiva na economia globalizada.

A partir do exposto, é possível dizer que a complexidade das transformações de mercado, exige dos gestores, tanto das empresas de capital quanto das cooperativas, novas habilidades e competências e sabendo que o sucesso das organizações depende essencialmente da qualificação de seus gestores, as cooperativas requerem diretores, gerentes, líderes, enfim, uma equipe administrativa qualificada capaz de administrar adequadamente a organização da qual faz parte.

\subsection{Recrutamento e Treinamento do Capital Humano das Cooperativas}

As organizações cooperativas, por se tratarem de organizações diferenciadas exigem profissionais diferenciados, e por esse motivo encontram dificuldades no processo de recrutamento de pessoal da organização, principalmente para cargos de gestão, pois as cooperativas precisam recrutar profissionais aptos para esses 
cargos. Por sua vez, estes profissionais estão inseridos no mercado capitalista e trazem consigo os valores criados pelo meio, valores de competição e que não levam em conta a cultura da cooperação e da solidariedade dentro da organização.

Para Davis e Bialoskorski Neto (2010) é de fundamental importância que exista uma seleção adequada dos candidatos para gerenciar a organização cooperativa, pois os gestores recrutados precisam ter o perfil compatível com a organização. O processo de recrutamento e seleção de uma cooperativa exige um cuidado maior, pois os candidatos procurados precisam atender as necessidades da mesma. O candidato a possível vaga não pode apenas ocupar um cargo dentro da organização, ele precisa entender o seu papel, bem como, entender as particularidades do sistema cooperativista e as singularidades da gestão.

Considerando as condições singulares da gestão de uma cooperativa, a organização precisa se preocupar com uma gestão segura e efetiva em relação aos seus aspectos culturais. E para que isso ocorra, os gestores contratados precisam atender aos critérios exigidos. Para encontrar o melhor candidato para assumir o cargo, a cooperativa pode utilizar dois processos, o recrutamento interno (recrutando funcionários já atuantes na cooperativa) e externo (recrutando pessoal do mercado de trabalho).

Independente do tipo de recrutamento a cooperativa precisa estar ciente do papel fundamental que os gestores contratados têm em dar suporte aos diretores eleitos. Para Davis e Bialoskorski Neto (2010), as cooperativas correm o risco de perder os seus verdadeiros propósitos se não desenvolverem uma cultura de gestão sólida, mas principalmente vão perder aquilo que é sua principal vantagem competitiva no mercado, a sua identidade. "Em suma, essas organizações poderão fracassar sem a mobilização do capital humano e do conhecimento que estão, potencialmente, a sua disposição. Assim, um processo de Gestão Cooperativista de Capital Social é de fundamental importância" (DAVIS; BIALOSKORSKI NETO, 2010, p. 22 ).

Para tanto, é importante investir na formação de recursos humanos, pois somente por meio disso é que será possível, o sucesso da cooperativa, se esta estiver ciente de que "não se constrói uma cooperativa, sem recursos humanos treinados, educados e motivados" (RODRIGUES, 2008, p. 249).

A formação desse profissional diferenciado coloca às sociedades cooperativas o desafio de estruturar processos internos de qualificação e capacitação, ou então 
externamente, quando deveriam desafiar as instituições formadoras a oferecer cursos voltados a essa área, ou pelo menos com conteúdos essenciais direcionados a essa ênfase (DREWS, 2000, p. 38).

Davis e Bialoskorski (2010, p. 21) enfatizam a necessidade da existência de um programa de educação cooperativista "[...] para auxiliar os gestores cooperativistas a atuarem em um contexto muito diferente daquele da grande maioria dos administradores, isto é, em empresas que objetivam apenas o lucro e o capital". Segundo Cohim Farias (2006) os gestores contratados precisam conhecer de forma global a organização que está sob sua gerência. Para esta mesma autora as técnicas de administração não são suficientes para que se alcance os resultados desejados em uma cooperativa, pois essa necessita de uma administração diferenciada.

Com esta afirmação, fica evidente a importância da cooperativa, preocupar-se com o seu capital humano e investir em programas de treinamento adequados às suas necessidades, principalmente, treinamentos voltados às particularidades da cooperativa e do movimento cooperativista em si. Para se sentir parte da organização qualquer profissional precisa conhecê-la e entendê-la, ainda mais se este não tem uma cultura de cooperação e traz consigo as marcas do individualismo deixadas pelo contato com o regime capitalista.

Por essa razão, é necessário que exista um programa de educação cooperativa continuada, pois somente através dessa ferramenta os gestores entenderão com clareza o diferencial da sua organização, proporcionando crescimento e competitividade institucional através da profissionalização da gestão, e consequentemente, o cooperativismo terá êxito na guerra por mercados.

\section{ASPECTOS METODOLÓGICOS}

Este artigo apresenta abordagem qualitativa e trata-se ainda de um estudo de caso. A escolha da organização-alvo para este estudo de caso foi pelo fato das cooperativas agropecuárias assumirem um importante papel, tanto para a economia brasileira quanto para os produtores rurais, e ainda por ser o setor mais forte economicamente do cooperativismo brasileiro. A organização escolhida é a Cooperativa Agropecuária Júlio de Castilhos COTRIJUC. 
Para a coleta dos dados foram utilizados os seguintes instrumentos: coleta documental referente à COTRIJUC, entrevista aberta com o diretor administrativo, entrevista semiestruturada com a responsável pelo setor de recursos humanos da cooperativa e ainda, a aplicação de questionário com perguntas abertas aos gestores contratados da COTRIJUC. Para a escolha da amostra, quais gestores contratados da organização responderiam aos questionários, foi utilizado o método não probabilístico, pois foram analisados os cargos de gestão contratados mais altos do organograma da cooperativa. Para facilitar o processo de aplicação dos questionários esses foram enviados através do e-mail de lideranças da própria COTRIJUC.

De acordo com o objetivo desta pesquisa, os cargos de gestão selecionados do organograma para a análise, foram os cargos contratados e de mais alto nível, ou seja, os três diretores (Diretor Comercial de Grãos, Administrativo e Financeiro e Comercial de Insumos), bem como, seus respectivos líderes de setor (Moinho, Grãos, Cerealista, Logística, Comunicação, TI, Manutenção, Contabilidade, Financeiro, RH, Postos de Combustíveis, Mercado, Setor Técnico, Rações, Leite, Sementes, Insumos Agrícolas, Insumos Pecuários, Máquinas e Implementos, e Peças e Equipamentos). Todos podem ser visualizados na Figura 1 que apresenta o organograma da Cooperativa em questão.

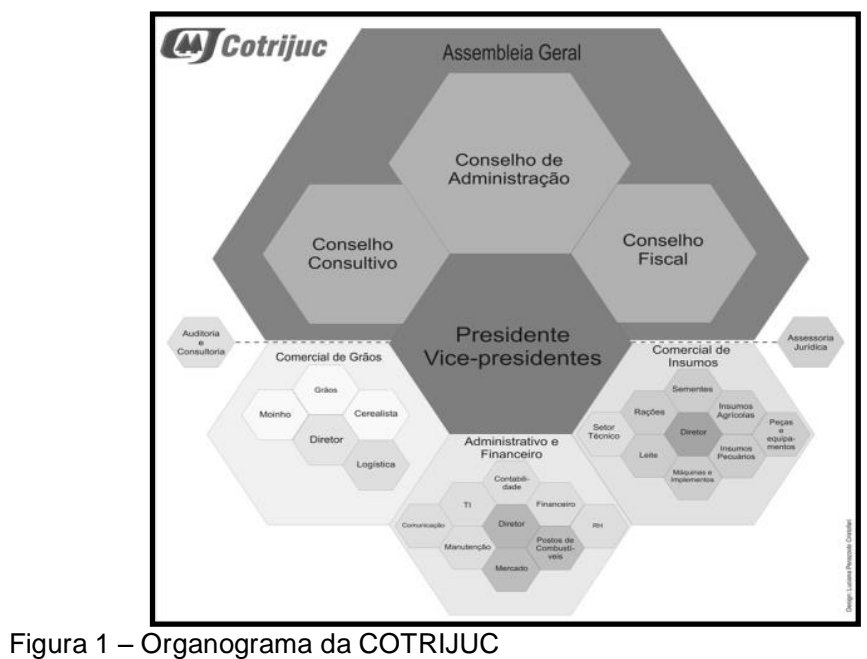

Fonte: COTRIJUC (2012) 
Os gestores contratados foram escolhidos pela sua influência na tomada de decisões e no suporte que os mesmos dão aos dirigentes associados da Cooperativa. É importante salientar que os três Diretores foram escolhidos, pois os mesmos são contratados e fazem parte da diretoria da Cooperativa, já os Líderes de Setor foram escolhidos, pois esses têm um papel maior do que apenas liderar o setor.

A escolha foi feita, justamente, pela cooperativa depender essencialmente da qualificação de seus gestores para obter sucesso, ela requer que sua equipe administrativa seja qualificada e adequada para administrar a complexidade do negócio, confirmando a afirmação de Rodrigues (2008, p. 333), "[...] os líderes eleitos definem o rumo, mas os profissionais pavimentam o caminho".

Dos vinte e três cargos de gestão selecionados para a amostra - três Diretores da cooperativa e vinte Líderes Setoriais -, quatorze gestores, ou seja, $60,87 \%$ responderam ao questionário, sendo que destes, onze são Líderes Setoriais e três deles Diretores da COTRIJUC.

\section{DISCUSSÃO DOS RESULTADOS}

\subsection{Cooperativa Agropecuária Júlio de Castilhos - COTRIJUC}

A Cooperativa Agropecuária Júlio de Castilhos - COTRIJUC - localizada na cidade de Júlio de Castilhos na região central do estado do Rio Grande do Sul foi fundada em 12 de março de 1950. A cooperativa no momento da pesquisa (2012/II) possuía um quadro social com 2.941 cooperados, a maioria são agricultores familiares mais de $70 \%$ do quadro social é formado por mini ou pequenos produtores. No decorrer dos 62 anos, a COTRIJUC ganhou força e conquistou espaço no mercado, atualmente, atua nas três esferas mercado regional, nacional e internacional.

A cooperativa configura-se como a maior organização da sua área de ação, nos seis municípios da região onde suas unidades estão presentes, Julio de Castilhos, Pinhal Grande, Ivorá, Itaara, Quevedos e São Martinho da Serra. Além disso, a mesma é a maior empregadora privada de sua área de atuação, tem 236 funcionários efetivos e contrata 80 funcionários a mais em época de safra. Outro ponto importante é a sua participação de mercado na área de ação (nos seis municípios) tanto para grãos comerciais quanto na comercialização dos insumos para as lavouras. A partir do exposto, é possível verificar a visão da cooperativa nesse contexto, "ser a melhor opção de negócio ao cooperado na proporção da sua 
participação e servir como referencial competitivo" (COTRIJUC, 2012, s.p.).

A expressiva participação mercadológica da COTRIJUC mostra um significativo grau de competitividade da organização, fator essencial para a sua sobrevivência na "guerra por mercados". Para entrar nesta guerra e continuar nela sem perder o seu espaço no mercado, a cooperativa teve que se tornar eficiente e remetendo à afirmação de Machado Filho et al. (2004), a cooperativa teve que "se adequar, tanto no que diz respeito à sua estruturação organizacional quanto à formulação de estratégias de negócios".

Como qualquer outra organização cooperativa, o órgão máximo da COTRIJUC, é o seu quadro social, onde as decisões são tomadas nas assembleias gerais da cooperativa, isso pode ser observado na Figura 1 que mostra claramente no organograma a escala de importância organizacional da cooperativa. Em seu estudo, Rossés et al. (2010) verificaram que a COTRIJUC adota uma postura de gestão compartilhada, onde o poder decisório da alta gestão é descentralizado, "as decisões estratégicas são tomadas pelo Comitê de Administração e aquelas de maior repercussão são compartilhadas com o Conselho de Administração, garantindo ainda aos cooperados, liberdade de intervenção no processo, sem preocupação com quebra de autoridade organizacional" (ROSSÉS et al., 2010, p. 9). Esse fator de descentralização do processo decisório proporciona à Cooperativa uma eficaz estratégia para vencer um dos principais problemas enfrentados no cooperativismo, que é a dificuldade em equilibrar na gestão os aspectos singulares de uma organização cooperativa (econômico, social e ambiental).

Outro fato de extrema relevância observado na estrutura organizacional da COTRIJUC mencionado pelo Diretor administrativo é o suporte que os gestores contratados dão ao quadro social e à direção no processo de tomada de decisões, pois estes gestores são os atores que participam ativamente no dia a dia do processo de gestão da COTRIJUC. A partir disso, se retoma a colocação de Rodrigues (2008), de que a complexidade das transformações do mercado exige dos gestores novas habilidades e competências, pois o sucesso da organização cooperativa depende essencialmente da qualificação dos gerentes, diretores e líderes. Dessa forma, é visto que a Cooperativa em questão preocupa-se em manter uma equipe competente e capaz de dar o suporte necessário na tomada de decisões, e essa preocupação é importante ressaltar, pois vai ao encontro com a ideia de Haas e Reisdorfer (2012) em que não há mais espaço para administradores amadores, curiosos ou aprendizes em um mundo onde os negócios estão extremamente complexos. 


\subsection{Processo de recrutamento e seleção na COTRIJUC}

De acordo com as normas internas de Recrutamento e Seleção, estabelecidas pela direção da cooperativa, o processo de recrutamento é norteado pelas diretrizes estratégicas do Setor de Recursos Humanos $(\mathrm{RH})$ da COTRIJUC. O recrutamento é determinado a partir do encaminhamento da requisição de pessoal pelo líder de setor, ao setor de Recursos Humanos. Mediante a requisição, é iniciado o processo, o qual prioriza, de acordo com a política de promoções internas, o recrutamento interno. Este considera a formação, experiência e desempenho do funcionário. $O$ recrutamento interno é apresentado pela cooperativa como forma de reconhecimento e incentivo ao desenvolvimento dos funcionários, bem como, este recrutamento é interessante pelo fato do funcionário já estar ambientado com o tipo de organização e com a cultura organizacional.

O processo externo de recrutamento e seleção é acionado quando a necessidade não é suprida pelo processo interno, a divulgação da vaga é feita através dos programas de rádio da cooperativa, cartazes nos locais de acesso público e nos próprios estabelecimentos dos setores. Na sequência, pré-selecionam-se os candidatos que atendem aos requisitos da vaga, fundamentados no documento perfil de cargos e agenda-se com estes uma primeira fase, na qual é realizada uma avaliação psicológica. Após, encaminha-se para uma segunda etapa os candidatos que obtiveram desempenho satisfatório. Esta segunda etapa consiste em uma entrevista individual, coletiva ou com dinâmicas de grupo. Em seguida, alguns candidatos são indicados para uma terceira fase, a entrevista individual do candidato, com os componentes do Comitê de Contratação, composto pelo presidente ou vice-presidente, um diretor contratado, o líder do setor envolvido e líder do setor de $\mathrm{RH}$, psicólogo, possibilitando um elevado nível de segurança no processo.

A seleção do candidato à vaga é estabelecida por consenso do comitê, visando reprimir qualquer espécie de discriminação e preconizando os princípios de justiça, dignidade, igualdade e individualidade das pessoas. No processo de recrutamento e contratação não há nenhuma espécie de vantagem para os candidatos, interferência ou indicação por parte dos cooperados, a vaga é preenchida única e exclusivamente pelas características adequadas ao cargo. 
Segundo a responsável do $\mathrm{RH}$, a maior dificuldade percebida no processo de contratação dos gestores é encontrar o perfil de liderança exigido, encontrar profissionais que entendam como gerenciar conflitos e principalmente tratando-se de uma cooperativa, que este profissional entenda as particularidades da cooperativa, não apenas gerenciar conflitos no quadro funcional, mas fundamentalmente entender que a clientela dessa organização também é dona do empreendimento. A colocação da responsável pelo processo de contratação reafirma o que Davis e Bialoskorski Neto (2010) apontam, os autores discutem a importância do processo de recrutamento e seleção dentro de uma cooperativa. Eles afirmam que a exigência e o cuidado devem ser maiores em uma organização que possui particularidades específicas, já que os candidatos recrutados não podem apenas ocupar um cargo dentro da organização, eles precisam entender o seu papel dentro da mesma, bem como, entender as particularidades do sistema cooperativista e as singularidades da gestão de uma cooperativa.

A preocupação com a contratação de gestores preparados e capacitados para auxiliar nos processos de gestão da COTRIJUC é coerente com a preocupação de uma gestão eficiente e preocupada em atender as exigências do mercado, e isso se comprova claramente quando a Líder do $\mathrm{RH}$ menciona um fato relevante, que é a baixa rotatividade nos cargos de liderança, pois estes vêm com um histórico de trabalho dentro da cooperativa, ou seja, já estão habituados ao ambiente organizacional, bem como, possuem familiaridade com a organização. Com isso, percebe-se que a identidade cooperativa é algo extremamente presente na COTRIJUC, os colaboradores entendem que gerenciar uma cooperativa é diferente de gerenciar outro tipo de organização, pois estes em grande maioria são colaboradores a um longo tempo na Cooperativa.

De forma contrária, no processo de recrutamento e seleção externo, enfatizado pela responsável do $\mathrm{RH}$, a quantidade de candidatos que tem algum conhecimento prévio sobre cooperativismo e sobre o funcionamento da gestão de uma cooperativa, é um número bastante pequeno, ou quase nulo dependendo do cargo aberto para seleção. Considera-se esse aspecto negativo, pois como afirma Cohim Farias (2006) os gestores contratados precisam conhecer de forma global a organização que está sob sua gerência. Para esta mesma autora as técnicas de administração não são suficientes para que se alcancem os resultados desejados em uma organização cooperativa, pois se trata 
de uma organização que necessita de uma administração diferenciada.

Ao final do processo de seleção, todos os funcionários ao serem contratados, participam do Programa de Integração da COTRIJUC realizado pela líder do $\mathrm{RH}$. Segundo 0 material disponibilizado pela cooperativa, este Programa tem o objetivo de "transmitir aos novos integrantes da organização, conhecimentos sobre a estrutura da cooperativa e seu sistema de trabalho; a filosofia organizacional, missão, visão, valores, política e objetivos da qualidade; os benefícios oferecidos e os programas de qualidade". Os funcionários recebem o manual de conduta ética da cooperativa e orientações referentes à sua segurança no trabalho. Após, os novos integrantes são encaminhados para conhecer as instalações da organização e os setores, oportunidade em que são apresentados aos outros colaboradores e também o momento de agendamento dos treinamentos iniciais com os setores de apoio. Isso acontece para que os novos contratados possam iniciar suas funções com alguns padrões estabelecidos, sendo que receberão os treinamentos específicos de sua função conforme a necessidade específica. Esta última etapa contempla o cadastramento de senhas de acesso ao sistema, ao e-mail e intranet.

\subsection{Gestores contratados da COTRIJUC}

A partir da análise dos questionários aplicados aos gestores contratados, verificou-se que a maioria $71,43 \%$ dos respondentes é do sexo masculino e apenas $28,57 \%$ do sexo feminino. Relacionado à faixa etária, 57,14\% tem idade entre 25 e 40 anos, 35,71\% tem de 41 a 60 anos, ainda um dos líderes não respondeu à pergunta. Referente à escolaridade, $28,57 \%$ têm ensino médio completo e $64,28 \%$ possuem ensino superior completo, destes $35,71 \%$ da amostra total são pós-graduados, um gestor não respondeu a esta pergunta. Com relação ao tempo de trabalho na COTRIJUC verificou-se à média de 12,3 anos, sendo que o mínimo de tempo de um dos respondentes é de um ano e dez meses e o maior tempo de trabalho é de trinta e dois anos.

Os entrevistados foram questionados sobre qual a relação que tinham com a cooperativa antes da sua contratação. Oito dos entrevistados responderam que não tinham nenhuma relação direta com a COTRIJUC e um destes afirmou que desconhecia da existência da mesma. A ligação de quatro dos gestores com a cooperativa antes de sua contratação era por terem algum familiar associado, um entrevistado mencionou que era estagiário da 
cooperativa e outro disse que antes de ser contratado pela cooperativa era cliente da mesma.

Sobre a forma de recrutamento dos gestores atuais, os entrevistados foram questionados se participaram de recrutamento interno ou externo. Dos gestores atuais, $85,71 \%$ foram selecionados para o cargo através de recrutamento interno, estão incluídos nessa parcela os três diretores e nove líderes setoriais. Apenas, dois gestores responderam que foram contratados por recrutamento externo $^{5}$. Este dado confirma as colocações da Líder de $\mathrm{RH}$, em que a prioridade é sim a contratação por recrutamento interno e, além disso, a afirmação da baixa rotatividade nos cargos de gestão, já que a Cooperativa exige certas especificações e qualidades nos cargos exigidos.

Com isso é perceptível a valorização por parte da COTRIJUC para com os seus colaboradores, incentivando e motivando o desenvolvimento de seus funcionários e permitindo o seu crescimento dentro da organização. Isso remete a ideia de Rodrigues (2008) de que os profissionais contratados além de dominar a complexidade dos negócios da organização, precisam conhecer as particularidades da cooperativa, sendo necessário saber que estão dentro de um sistema diferenciado e que precisam levar em conta os aspectos culturais da organização para o efetivo empenho das suas funções. Na COTRIJUC, percebe-se que esse conhecimento é primordial para a ocupação de cargos de liderança da Cooperativa, por esse motivo a maioria dos atuais gestores da Cooperativa são colaboradores selecionados através de recrutamento interno.

Quando questionados se já haviam trabalhado em outra cooperativa antes de serem contratados pela COTRIJUC, 92,85\% responderam que não, apenas um disse que estagiou na Cooperativa Agrícola Mista Santa Mariense Ltda. - COASA - que hoje não está mais em funcionamento. Ao serem questionados sobre

5 É importante salientar, que embora a maioria dos gestores tenham sido selecionados por recrutamento interno, o que significa que já possuíam algum conhecimento prévio acerca da organização, os mesmos, antes de serem gestores, ou até mesmo, antes de entrarem na cooperativa (em outro cargo) metade não o possuía como será visto posteriormente. Dessa forma, é possível que a resposta da amostra tenha sido dada em relação a este último aspecto. Vale destacar também, que tanto para esse questionamento quanto para as demais questões, os entrevistados podem ter entendido a contratação por recrutamento interno, para os cargos de gerência ou liderança, ou ainda, para os antigos cargos que ocupavam na cooperativa (recrutamento externo). 
o conhecimento prévio que possuíam a respeito do cooperativismo e das particularidades da gestão de uma cooperativa no momento da contratação, metade dos gestores analisados apontou que não tinha conhecimento nenhum sobre 0 assunto, já a outra metade afirma que possuía algum tipo de conhecimento prévio. Porém alguns afirmam ser apenas uma noção sobre o conceito básico de cooperativismo ${ }^{6}$.

Foi solicitado para os entrevistados que possuíam algum tipo de conhecimento sobre cooperativismo que informassem como ficaram sabendo. Dois dos entrevistados disseram ter conhecimento sobre cooperativismo, pois ao serem contratados já eram estagiários da Cooperativa, dois afirmaram ter conhecimento básico sobre esse assunto por meio de familiares associados em outras cooperativas e por fim três gestores disseram ter noção do assunto, pois na época algum familiar era associado da COTRIJUC, sendo que um destes comentou o fato de ter tido uma disciplina na faculdade.

Levando em consideração os dados apresentados anteriormente, foi buscado analisar a percepção dos gestores sobre a necessidade do conhecimento prévio de cooperativismo no processo de gestão e se existem dificuldades nesse processo na falta desses conhecimentos prévios. A maioria dos líderes de setores da COTRIJUC entende que, a falta de conhecimento prévio sobre cooperativismo não dificulta o processo de gestão, suas justificativas estão relacionadas ao fato de existir o Programa de Integração, no momento de admissão, que traz esclarecimentos sobre 0 assunto. Também justificam pelo fato de que seus colegas mais antigos ensinam e dão apoio aos novos colaboradores nesse sentido.

Os líderes que avaliaram ser relevante o conhecimento prévio sobre cooperativismo e que a falta dele dificulta o processo de gestão, fizeram as seguintes colocações: São importantes, pois são vários setores que fazem parte de uma Cooperativa, cada qual com suas particularidades para serem administrados segundo os princípios de cooperativismo (LÍDER 1, 2012).

Acredito que o conhecimento prévio sobre o cooperativismo contribui para atuação inicial do gestor, facilitando a interação com os

${ }^{6}$ Novamente, destaca-se que alguns dos entrevistados passaram pelo processo de recrutamento interno, ou seja, alguns cargos de gerência e liderança foram ocupados por profissionais que já atuavam na cooperativa. Sendo assim, esses, adquiriram conhecimento sobre o cooperativismo no diaa-dia de trabalho. 
cooperados, porém não interfere na execução de processos (LÍDER 3, 2012).

Quando iniciei meu trabalho como gestora já estava ambientada com o sistema cooperativo. por ter atuado durante três anos como analista do setor de $\mathrm{RH}$, tive esse tempo de aprendizado prévio que com certeza me favoreceu (LÍDER 8, 2012).

Seguindo a mesma linha destes três líderes, os três diretores da Cooperativa, também avaliam ser de extrema importância $o$ fato de se ter um conhecimento prévio sobre cooperativismo quando o colaborador assume algum cargo na cooperativa. Um dos diretores disse que quando se tem esse conhecimento há um maior aproveitamento no processo de gestão. Os outros diretores mencionaram que:

Sim se, se tratar de Líderes e Diretores, pela necessidade de conhecimento de ambiente para entendimento da importância dos fatores e questões que se apresentam nos momentos de processos decisórios (DIRETOR 3, 2012).

Sim, trabalhadores que iniciam as atividades em uma cooperativa sem conhecimento básico do sistema e da lei das cooperativas, certamente enfrentarão dificuldades na operação, na gestão e também na esfera tributária (DIRETOR 1, 2012).

Ao serem questionados sobre a importância de existir um treinamento específico sobre o cooperativismo, todos os gestores contratados da COTRIJUC afirmam que, é de extrema importância existir um treinamento nesse sentido. A justificativa desta afirmação dita pelos gestores está nas suas explicações um dos gestores aponta que, "é importante para que os novos colaboradores conheçam o ambiente onde vão trabalhar, porque cooperativa é diferente de empresa privada" (LÍDER 10, 2012). Outros gestores ainda colocam, de uma forma ou outra, a importância de que todos os colaboradores tenham o conhecimento dos conceitos sobre cooperativismo e entendam os interesses e a finalidade da cooperativa. Além disso, indicam importância tanto da direção quanto dos colaboradores aprimorarem os seus conhecimentos já existentes sobre a temática para aplicação diária desses. Outros líderes ainda disseram que: 
Com certeza é importante, para que o funcionário tenha noção sobre o sistema cooperativo que o deixará confortável junto ao ambiente de trabalho favorecendo a ambientação junto aos processos (LÍDER 8, 2012).

É estranho entrar em uma organização e não saber o que ela faz, qual suas principais metas e sua filosofia, pois não é só trabalhar por trabalhar, temos que saber de onde viemos e onde queremos chegar (LÍDER 7, 2012)

É importante salientar, a visão de um dos diretores da COTRIJUC sobre esse conhecimento no processo de recrutamento externo:

Quando a contratação for externa para algum cargo de liderança ou direção e o funcionário não tenha conhecimento prévio adequado. É necessário que este treinamento seja aderente a realidade do quadro social desta cooperativa e do contexto mercadológico em que ele está inserido (DIRETOR 3, 2012).

Um último aspecto sobre essa questão é a colocação de dois líderes a respeito da importância do programa de educação cooperativa para a atualização dos gestores, para que dessa forma o sistema cooperativista possa seguir evoluindo atingindo as futuras gerações. Com estas indicações, percebe-se uma importância por parte das cooperativas, ao investirem no seu capital humano, fundamentalmente quando relacionado a treinamentos e capacitações voltadas às especificidades de uma organização cooperativa e do movimento que as direcionam.

\section{CONSIDERAÇÕES FINAIS}

A sobrevivência do cooperativismo em um mundo cada vez mais dinâmico e competitivo depende essencialmente da maneira que as organizações cooperativas estão se adaptando as essas constantes mudanças e transformações dos ambientes e dos negócios. As cooperativas são organizações diferenciadas, seus propósitos e objetivos são baseados em uma doutrina própria, sua identidade é fundamentada em características peculiares, a organização precisa manter o equilíbrio das dimensões, econômico, 
social e ambiental, diferentemente das outras organizações que visam somente o lucro e são baseadas nos moldes capitalistas.

Percebe-se com evidência, e que as cooperativas estão envolvidas em uma complexa realidade e que a sua gestão precisa ser profissionalizada. Porém, conforme Rodrigues (2008) afirma não se pode profissionalizar a gestão de uma cooperativa como outra empresa qualquer, pois ela não é. $O$ quadro de gestores da cooperativa precisa ser qualificado adequadamente para administrar com eficiência a complexidade das transformações de mercado sem perder a identidade cooperativa, dessa forma gerenciando esse empreendimento acordo com seus preceitos.

A partir disso, as cooperativas têm uma preocupação pertinente em relação aos seus gestores, tanto em relação às lideranças eleitas, quanto aos colaboradores contratados. Principalmente as organizações cooperativas precisam se preocupar com estes últimos, já que são profissionais que estão "No mercado capitalista, e sua formação foi definida sob regime do lucro" (RODRIGUES, 2008, p. 246). É fundamental que os profissionais contratados conheçam as singularidades da cooperativa, conheçam o sistema cooperativo e que estes, levem em conta os aspectos culturais da organização onde trabalham, para o efetivo desempenho de suas funções.

Este estudo teve por objetivo analisar se o gestor contratado da COTRIJUC compreende as especificidades de uma organização cooperativa e se isto auxilia no processo de gestão. Analisando os resultados obtidos por meio dos métodos de pesquisa utilizados, foi possível pontuar algumas considerações que tem relação direta com o objetivo deste estudo.

Foi constatado que $85,71 \%$ dos gestores entrevistados foram selecionados através de recrutamento interno para os cargos de liderança, isso justifica a característica dos gestores de terem conhecimentos específicos sobre cooperativismo e a forma de gerenciamento de cooperativas. Esses atuais gestores da cooperativa estão atuando na mesma, em média 12,3 anos, esse dado mostra que o tempo de trabalho na organização fez com que fossem aprimorados os seus conhecimentos sobre este tema e também proporcionou aos colaboradores o entendimento sobre o seu papel dentro da organização e da complexidade da mesma.

Uma característica relevante percebida na COTRIJUC é o envolvimento dos seus gestores com a organização, ficou claro que os líderes e diretores entrevistados conhecem e entendem o seu importante papel dentro da organização, pois são eles que dão o 
suporte necessário para que a cooperativa continue ativa no mercado, atendendo eficientemente os seus cooperados.

Por fim, outro fator de relevância percebido durante a análise do estudo foi que a COTRIJUC embora não tenha um programa de educação cooperativa, vem proporcionando ações informais de educação/capacitação cooperativa para seus colaboradores, pois através dos conhecimentos transmitidos dos colaboradores mais antigos aos novos colaboradores, estes entendem e podem vivenciar a cultura cooperativa dentro da própria Cooperativa. Com isso, sugere-se à cooperativa, que a mesma crie um programa de educação cooperativa continuada para os gestores e demais funcionários, para que todos os funcionários ao adentrarem e ao assumirem novos cargos, compreendam de fato o seu papel dentro da organização e o diferencial que esta tem perante a sociedade. Também é importante que as Cooperativas, assim como o órgão que representa às cooperativas façam parcerias com as instituições de ensino, pois estas são responsáveis pela formação dos futuros profissionais.

\section{REFERÊNCIAS}

ANTONIALLI, Luiz Marcelo. Influência da mudança de gestão nas estratégias de uma cooperativa agropecuária. RAC - Revista de Administração Contemporânea, Rio de Janeiro, v. 4, n.1, p. 135159, 2000.

ANTONIALLI, Luiz Marcelo; SOUKI, Gustavo Quiroga. Princípios cooperativistas e modelo de gestão: um estudo sobre conflitos de interesses entre grupos de produtores rurais. In: CONGRESSO BRASILEIRO DE ECONOMIA E SOCIOLOGIA RURAL, 2005, Ribeirão Preto-SP. Anais do XLIII Congresso Brasileiro de Economia e Sociologia Rural. Ribeirão Preto-SP: FEARP/USP Faculdade de Economia, Administração e Contabilidade da Universidade de São Paulo, 2005. v. 43. p. 1-19.

COHIM FARIAS, Sandra Mary. Gestão de cooperativa: um estudo de caso. 2006. 167 f. Dissertação (Mestrado em Desenvolvimento Humano e Responsabilidade Social) - Fundação Visconde de Cairu, Salvador, 2006.

COTRIJUC, Cooperativa Agropecuária Júlio de Castilhos. Disponível em <http://www.cotrijuc.com.br/site/>. Acesso em: 27 dez. 2012. 
DAVIS, Peter; BIALOSKORSKI NETO, Sigismundo. Governança e gestão de capital em cooperativas: uma abordagem baseada em valores. ESAC - Economia Solidária e Ação Cooperativa. Unisinos, v.5, n 01,p. 01-24, jan/jun 2010.

DEMO, Pedro. Metodologia científica em ciências sociais. 3. ed. São Paulo: Atlas, 1995.

DREWS, Gustavo Arno. Gestão de Recursos Humanos orientada ao Comprometimento: A Prática em Cooperativas do Noroeste do RS. 2000168 f. Dissertação (Mestrado em Administração) Universidade Federal do Rio Grande do Sul, Porto Alegre, 2000.

GIL, Antonio Carlos. Como elaborar projetos de pesquisa. 4 ed. São Paulo: Atlas 2002.

HAAS, Fernando Reichert; REISDORFER, Vitor Kochhann. Estudos de casos: Modelos de gestão e políticas adotadas nas cooperativas de produção e comercialização da agricultura familiar na microrregião de cerro Largo RS - Brasil. In: II Encontro Brasileiro de Pesquisadores em Cooperativismo. Porto Alegre, 2012.

JERÔNIMO, Fátima Behncker. MARASCHIN, Angela de Faria. SILVA, Tania Nunes. A gestão estratégica de sociedades cooperativas no cenário concorrencial do agronegócio brasileiro: estudo de caso em uma cooperativa agropecuária gaúcha. Teoria e Evidência Econômica, v. 14, n. 26, p. 71-89. Passo Fundo, 2006.

MACHADO FILHO, Cláudio Antônio Pinheiro; MARINO, Matheus Kfouri; CONEJERO, Marco Antonio. Gestão Estratégica em Cooperativas Agroindustriais. Caderno de Pesquisas em Administração. USP, v. 11, p. 61-69, 2004.

OCB - Organização das Cooperativas Brasileiras. Números do cooperativismo brasileiro. Brasília: Departamento Técnico e Econômico, Banco de Dados. Disponível em <http://www.ocb.org.br>. Acesso em 27 dez. 2012.

RODRIQUES, Roberto. Cooperativismo: Surfando a segunda onda. São Paulo: [s.n.], 2008. 487 p.

ROESCH, Sylvia Maria Azevedo. Projetos de Estágio do Curso de Administração: guia para pesquisas, projetos, estágios e trabalhos de conclusão de curso. São Paulo: Atlas, 1999.

ROMÃO, Gabriela Araújo. CONFORTI, Thiago Teixeira. LIMA, Tereza Cristina Pinheiro de. Perfil de gestão: um estudo de caso em 
uma cooperativa agroindustrial. In: VIII Congresso Nacional de Excelência em Gestão. Rio de Janeiro, 2012.

ROSSÉS, Gustavo Fontinelli; et al.. Sistema de Gestão em Cooperativas: o caso da Cooperativa Agropecuária Júlio de Castilhos. In: VII SEGET - Simpósio de Excelência em Tecnologia e Gestão, 2010, Resende. Anais do VII SEGET, 2010.

SESCOOP - Serviço Nacional de Aprendizagem do Cooperativismo. Diagnósticos e Recomendações. Série Desenvolvimento em Cooperativas. SESCOOP, 2008.

VALADARES, José Horta. Moderna administração de cooperativas. Belo Horizonte, maio 2002. (Apostila FORMACOOP Mód.II )

YIN, Robert K. Estudo de Caso: planejamento e métodos. 2. ed. Porto Alegre: Bookman, 2001.

ZYLBERSZTAJN, Décio. Quatro estratégias fundamentais para cooperativas agrícolas. In: BRAGA, Marcelo José; REIS, Brício dos Santos (Org). Agronegócio Cooperativo - reestruturação e estratégias. Viçosa, 2002. 